\title{
IV Congreso Nacional de Investigaciones en Antropología
}

\section{Alejandro Diez}

\section{Q OpenEdition}

1 Journals

\section{Edición electrónica}

URL: http://journals.openedition.org/bifea/5556

DOI: $10.4000 /$ bifea.5556

ISSN: 2076-5827

\section{Editor}

Institut Français d'Études Andines

\section{Edición impresa}

Fecha de publicación: 1 agosto 2005

Paginación: 266-267

ISSN: 0303-7495

\section{Referencia electrónica}

Alejandro Diez, « IV Congreso Nacional de Investigaciones en Antropología », Bulletin de l'Institut

français d'études andines [En línea], 34 (2) | 2005, Publicado el 08 agosto 2005, consultado el 01

diciembre 2020. URL : http://journals.openedition.org/bifea/5556 ; DOI : https://doi.org/10.4000/bifea. 5556

\section{(c) 989}

Les contenus du Bulletin de l'Institut français d'études andines sont mis à disposition selon les termes de la licence Creative Commons Attribution - Pas d'Utilisation Commerciale - Pas de Modification 4.0 International. 


\section{CONGRESO NACIONAL DE INVESTIGACIONES EN ANTROPOLOGÍA}

El IV congreso nacional de investigaciones en antropología se desarrolló de acuerdo a lo previsto, entre el $1^{10}$ y el 6 de agosto de 2005. La organización estuvo a cargo de un comité compuesto por tres profesores de la Universidad Nacional Mayor de San Marcos (Román Robles, Mercedes Giesecke y Rommel Plascencia) y tres de la Pontificia Universidad Católica del Perú (Gisela Cánepa, Cecilia Rivera y Alejandro Diez); a ellos se les sumaron Humberto Rodríguez del CONCYTEC y Juan José García del INC.

La realización del Congreso fue posible en gran medida por el acuerdo institucional entre ambas universidades, establecido oficialmente por sus máximas autoridades mediante la firma de un convenio de cooperación. Las diversas actividades se repartieron entre las dos universidades desarrollándose los tres primeros días en la UNMSM y los tres siguientes en la PUCP.

Entre las actividades académicas realizadas se cuenta el desarrollo de 47 simposios temáticos, 3 mesas de balance sobre investigaciones en antropología y 2 conferencias magistrales. Entre las presentaciones de estas tres actividades se alcanzó un total de 301 presentaciones académicas (280 ponencias en simposios, 19 ponencias de balance, 2 conferencias magistrales). Durante los días del congreso asistieron alrededor de 800 participantes inscritos, a los que se suman alrededor de 200 personas más que asistieron como participantes libres. La mayor parte de los asistentes fueron antropólogos graduados procedentes de las diversas universidades, centros de investigación y de promoción de diversas partes del país y del extranjero. Destacó también la presencia de delegaciones de estudiantes de provincias (215 personas), a los que se sumaron estudiantes de San Marcos, de la Universidad Católica y de la Villarreal.

Los días del congreso fueron ocasión para el desarrollo de una serie de actividades complementarias, entre las que se cuentan la presentación de 14 publicaciones, entre libros y revistas; la proyección de 22 vídeos y documentales sobre temas de interés antropológico, 


\section{Événements}

presentados por sus realizadores; la presentación de un ciclo de cine y la exhibición de documentales del taller de antropología visual de la PUCP; y, la realización de 9 exposiciones de temáticas y formatos diversos (bibliográficas, fotográficas y visuales y de objetos culturales) así como una feria de venta de publicaciones y artesanías. Destaca también la presentación del ciclo de Cine Jean Rouch, desarrollado gracias al auspicio de la Alianza Francesa de Lima.

El Congreso, «La Antropología ante el Perú de Hoy», se propuso actualizar el estado de la cuestión en la especialidad en el país. Por su dimensión y convocatoria, ha sido la más importante reunión de antropólogos peruanos y extranjeros de los últimos 20 años, sólo comparable al primer congreso, desarrollado en 1985. Académicamente ha convocado a antropólogos especializados en diversas ramas y facetas de la disciplina, desde los preocupados por problemas de política, ciudadanía, memoria, violencia, gobierno y temas afines hasta quienes se ocupan de temas de lenguaje, educación, imaginarios; convocó a quienes abordan temas clásicos como la economía campesina, la antropología de la religión hasta temas más contemporáneos como la migración internacional, la globalización y la etnicidad.

Destacaron en el congreso las tres mesas de balance convocadas. La primera, que brindó una visión panorámica de la antropología desde los espacios de investigación y ejercicio de la profesión en diversas regiones del país (Ayacucho, Amazonía, Arequipa, Cusco, Huancayo, Lima, Puno y Trujillo). La segunda buscaba poner en contexto la antropología peruana con sus similares latinoamericanas, contándose con ponencias de balance de Argentina (Roxana Guber, CACIDES), Bolivia (Freddy Michel, UNSA), Brasil (Otavio Velho, MNUFRJ), Ecuador (Segundo Moreno, PUCE), México (Guillermo de la Peña, CIESAS) y Perú (Alejandro Diez, PUCP). Finalmente, la tercera logró brindar un panorama de los estudios peruanistas en el exterior, contando con la presencia de Jürgen Golte (ULB, Alemania), Jean Pierre Chaumeil (CNRS, Francia), Carmen Salazar (IRD, Francia) y Penélope Harvey (U. Manchester, Gran Bretaña), así como con el texto escrito enviado por Hidefuji Tomoeda (U. Osaka, Japón).

El evento no habría sido posible sin el generoso apoyo de un sinnúmero de personas y el auspicio de numerosas instituciones entre las que destacan las universidades e institutos académicos del conjunto de ponentes de las mesas de balance; las instituciones que como el IFEA, el CONCYTEC, la Organización de Estados Iberoamericanos, el CIES, el CAAAP y el IDESI contribuyeron económicamente para el financiamiento del evento; y las instituciones que contribuyeron para la realización de las actividades complementarias a las mesas y simposios, cuya relación sería larga de enumerar.

La comisión organizadora se encuentra elaborando el balance del evento, compilando y revisando las ponencias recibidas para la elaboración de una memoria académica y visual, que se espera publicar en formato combinado digital y físico a la brevedad posible. El Quinto congreso Nacional de investigaciones en antropología ha sido encargado a la Universidad Nacional San Antonio Abad del Cusco. 